\title{
Probiotics as a Potential Alternative for Relieving Peripheral Neuropathies: a Case for Guillain-Barré Syndrome
}

\author{
Abhishek Saxena * \\ Department of Biotechnology, TERI University, New Delhi, India
}

Keywords: Guillain-Barré syndrome, peripheral neuropathies, neuronal autoimmunity, probiotics, microbiota, gut-brain axis

\section{INTRODUCTION}

Trillions of microorganisms form the "natural flora" of the human body. These microorganisms outnumber the host cells 10 to 1 , essentially making humans a microbial ecosystem of sorts. Before the advent of the high-throughput sequencing technologies such elusive microorganisms were uncultivable and could not be studied using traditional microbiological techniques. However, since the past decade, with the establishment of the Human Microbiome Project reference database in 2012, research in this area has grown logarithmically (Grogan, 2015). The human microbiota is introduced from mother to the fetus and even infants, and remains with the growing individual for

OPEN ACCESS

Edited by:

Ryo Inoue,

Kyoto Prefectural University, Japan

Reviewed by:

Mayuko Osada-Oka,

Kyoto Prefectural University, Japan

*Correspondence:

Abhishek Saxena asaxena87@gmail.com

Specialty section: This article was submitted to Microbial Immunology, a section of the journal

Frontiers in Microbiology

Received: 05 October 2015 Accepted: 11 December 2015 Published: 07 January 2016

Citation:

Saxena A (2016) Probiotics as a Potential Alternative for Relieving

Peripheral Neuropathies: a Case for Guillain-Barré Syndrome.

Front. Microbiol. 6:1497.

doi: 10.3389/fmicb.2015.01497 the rest of his/her life, being effected by and also affecting the individual's lifestyle, food habits, and metabolism. Friendly microbes have been shown to protect from several diseases and a dysbiosis in the microbiota has been linked to infections by pathogens, autoimmunity and lifestyle disorders. The establishment of the brain-gut axis (reviewed in Carabotti et al., 2015) in the past few years has even shown that gut microbiota and brain affect each other (Carabotti et al., 2015). A very recent study established the missing link between the central nervous system (CNS) and the immune system i.e., the CNS lymphatic vessels, thus completing the microbiota-neuronal-immune system triangle (Louveau et al., 2015). Even stress, and behavioral changes can result in an altered microbiota and vice-versa (Schmidt, 2015). This has brought microbiologists and neuroscientists together to look into the probable mechanisms in which dysbiosis of gut microbiota may affect development of neurodegenerative diseases and even neuronal autoimmunity.

Autoimmune diseases of both the central and the peripheral nervous system (PNS) have been linked to microbiota, although the extent to which the link has been established is very different. While some like multiple sclerosis (MS) has working mice-models, others like GuillainBarré syndrome (GBS), a rare autoimmune disorder of the PNS has no defined models, although experimental autoimmune neuritis (EAN) may be used to study some aspects of GBS, especially macrophage mediated demyelination (Kieseier et al., 2012). Even so, we have been warned against the fallacies of studying such models in isolation, as there is no strict one model-one disorder kind of relationship between human autoimmunity and mouse/rat model (Gold et al., 2000). Since probiotics have been found to be useful in the treatment of autoimmune diseases like Inflammatory Bowel Disease (IBD) (Sheil et al., 2007), type1 diabetes (Calcinaro et al., 2005) and even extra-intestinal neuronal and systemic-autoimmune disorders like MS (Lavasani et al., 2010) and systemic lupus erythematosus (SLE) (Manirarora et al., 2008; Alard et al., 2009), testing the efficacy of probiotics in the treatment of GBS might offer a less invasive and more acceptable and economical treatment alternative. 


\section{PROBIOTICS MODULATE THE GUT MICROBIOTA TO AFFECT THE HOST IMMUNE SYSTEM}

Altered gut microbiota or "gut dysbiosis" has been linked to autoimmune responses both intra-intestinally as well as extraintestinally. Recently concluded and active research has helped detail the mechanisms of interaction between the gut microbiota and the immune system (Maynard et al., 2012). Attempts to understand the mechanisms of restoration of healthy gut microbiota (eubiosis) by probiotics has started to reveal the complex interactions and signaling involved between the host cells including components of the immune system, the probiotic strain and the other commensal or pathogen residing in the host system (Wagner et al., 2009; Wine et al., 2009; Maynard et al., 2012; Bollrath and Powrie, 2013). It is generally accepted that adaptive immunity to microbes may be mediated by Toll-like receptors (TLRs), C-type lectin receptors (CLRs), and NODlike receptors (NLRs), which are present on the epithelium, endothelium, and lymphoid tissue of the host. These receptors might signal downstream depending upon the situation of eubiosis (homeostasis)/dysbiosis (Walker, 2008; Maynard et al., 2012). Traditionally, two T-cell fates have dominated the immune system related signaling viz. T-helper cell $\left(\mathrm{T}_{\mathrm{H}} 1\right)$ and $\mathrm{T}_{\mathrm{H}} 2 . \mathrm{T}_{\mathrm{H}} 1$ type response is elicited on exposure to pathogens and leads to their phagocytosis, causing inflammation to the surrounding host tissue and even autoimmune responses. $\mathrm{T}_{\mathrm{H}} 2$ type of response is elicited mainly on exposure to environmental cues and also some pathogenic proteins, leading to the production of $\operatorname{IgE}$ and release of histamines that counter $\mathrm{T}_{\mathrm{H}} 1$ response (Berger, 2000). Later studies have, however, revealed a much more complex picture of autoimmunity and has introduced new types of $\mathrm{CD}_{4}{ }^{+} \mathrm{T}$-cell viz. $\mathrm{T}_{\mathrm{H}} 17$ (Damsker et al., 2010) and $\mathrm{CD} 25^{+}$ $\mathrm{FoxP}^{+}$regulatory T-cells (Treg) (Sakaguchi et al., 2009). During immune homeostasis the concentration of Interleukin (IL-10) (also secreted by $\mathrm{T}_{\mathrm{H}} 2$ cells) secreting Treg cells dominate the intestinal mucosa. In most of the autoimmune conditions, a common feature seems to be diminished presence of Treg cells in the intestinal mucosa of the host resulting in a shift toward IL-17 secreting $\mathrm{T}_{\mathrm{H}} 17$ cells and this shift in the T-cell population seems to be dependent on the intestinal cytokine Transforming Growth Factor (TGF- $\beta$ ). Interestingly, in the face of pathogenic infection or an inflammation caused by the resident microbiota, the IL-10 secreting Treg cells are also converted to IL-17, Retinoic acid-related Orphan Receptor (ROR $\gamma \mathrm{T}$ ), and Interferon (IFN- $\gamma$ ) producing $\mathrm{T}_{\mathrm{H}} 17$ cells (Xu et al., 2007) and vice-versa (Gagliani et al., 2015). Research exploring the gut-brain axis has lead to an understanding that altered gut microbiota plays a role not only in gastrointestinal autoimmunity but also extra-intestinal autoimmunity. Systemic and neuro-autoimmunities like SLE and MS have been linked to gut dysbiosis, making a strong case for linking GBS to altered microbiota.

Our current understanding of the link between gut eubiosis and immune homeostasis, and the effect of probiotics on the former have been reviewed elsewhere (Hemarajata and Versalovic, 2013; Kueffel et al., 2013). Various studies have already tipped the balance toward the use of probiotics for providing relief in a number of diseases and disorders including extra-intestinal autoimmunities. As briefly mentioned above, a study has pointed toward the therapeutic effect of probiotic consisting of a mixture of lactobacilli on experimental autoimmune encephalomyelitis (EAE; an experimental model of MS) through IL-10 secreting Treg cells (Lavasani et al., 2010). In a later study, it has been shown that pro-inflammatory T-cell response consisting of IL-17A and IFN- $\gamma$ producing $\mathrm{T}_{\mathrm{H}} 17$ cells caused EAE in germ-free mice upon infection from Segmented Filamentous Bactria (SFB) (Lee et al., 2011), further linking gut dysbiosis and neuronal autoimmunity. Immunopathology of GBS too is complicated by $\mathrm{T}_{\mathrm{H}} 17$ cells and the corresponding cytokines, thus making it a balance between $\mathrm{T}_{\mathrm{H}} 1 / \mathrm{T}_{\mathrm{H}} 17$ and $\mathrm{T}_{\mathrm{H}} 2$, although mechanistic details are yet to be elucidated (Liang et al., 2012; Li et al., 2012, 2014). Functional aspects of $\mathrm{T}_{\mathrm{H}} 17$ cells and associated cytokines and their rational drug targeting with respect to GBS is discussed in some details elsewhere (Wang et al., 2013; Wu et al., 2015). Studies on the lines of drug trials have shown that in most stomach related ailments; probiotics do confer a health benefit (Mack, 2005). Some small studies in model organisms show that probiotics confer prophylactic or curative benefit against diabetes, certain cancers, Human Immunodeficiency Virus (HIV), rheumatoid arthritis, and MS among several other conditions (Erickson and Hubbard, 2000; Matsuzaki et al., 2007).

\section{GUILLAIN-BARRÉ SYNDROME: PROTOTYPE OF AN IMMUNE MEDIATED PERIPHERAL NEUROPATHY}

GBS is a post-infection autoimmune monophasic disorder of the PNS and is characterized by acute flaccid paralysis. The syndrome has variants categorized depending upon the kind of neuropathy viz. demyelinating or axon degenerating. These have been described in detail by Dimachkie and Barohn (2013) and have been summarized in the form of a table in this article (Table 1). The immunopathology of the GBS is not well understood however it is known that the syndrome occurs postinfection by Campylobacter jejuni (Kaldor and Speed, 1984; Allos, 1997), Mycoplasma pneumonia (Goldschmidt et al., 1980), certain Herpesviridae (Jacobs et al., 1998), HIV (Pontali et al., 2011) and flu viruses (Sivadon-Tardy et al., 2009) or in some cases after the administration of flu vaccine (Geier et al., 2003), most probably due to an imbalance in the various T-helper cell populations described above. Proinflammatory, $\mathrm{T}_{\mathrm{H}} 1$ type cytokines like Tumor Necrosis Factor (TNF- $\alpha$ ), IFN- $\gamma$, and IL1 have implicated in triggering mechanism of EAN/GBS. Other proinflammatory cytokines like IL-12, TNF- $\alpha / \beta$, and IL-2 are also detected during the course of the disease progression. $\mathrm{T}_{\mathrm{H}} 17$ cytokines IL-17 and IL-22 have also been detected in the serum of GBS patients thus confirming the role of $\mathrm{T}_{\mathrm{H}} 17$ mediated pro-inflammatory response ( $\mathrm{Li}$ et al., 2012). Interestingly, proinflammatory cytokines IL-4, IL-5, and IL-6, may be produced by cells expressing the rival $\mathrm{T}_{\mathrm{H}} 2$ phenotype, contributing to GBS. 
TABLE 1 | Variants of Guillain-Barré Syndrome.

\begin{tabular}{|c|c|c|c|c|}
\hline GBS variant & Symptoms & Mechanism of autoimmunity & Autoantigens implicated & Remarks/references \\
\hline AIDP & $\begin{array}{l}\text { Areflexia, mild sensory changes, distal } \\
\text { paresthesisas, loss of tendon reflexes, } \\
\text { ascending paralysis, respiratory failure }\end{array}$ & $\begin{array}{l}\text { Macrophages, T-cell } \\
\text { mediated demyelination }\end{array}$ & & Dimachkie and Barohn, 2013 \\
\hline AMSAN & $\begin{array}{l}\text { Loss of deep tendon reflex, distal weakness } \\
\text { and sensory aymptoms }\end{array}$ & $\begin{array}{l}\text { Auto antibodies against } \\
\text { nerve gangliosides }\end{array}$ & GD1a, GM1, GM1b & $\begin{array}{l}\text { Shoenfeld and Meroni, 2012; } \\
\text { Dimachkie and Barohn, } 2013\end{array}$ \\
\hline AMAN & $\begin{array}{l}\text { Accute, flaccid ascending paralysis, high } \\
\text { protein in the CSF, dysphagia, dysarthria, total } \\
\text { loss of refexes, and respiratory failure in } \\
\text { advanced cases }\end{array}$ & $\begin{array}{l}\text { Auto antibodies against } \\
\text { nerve gangliosides }\end{array}$ & $\begin{array}{l}\text { GD1a, GM1, GM1b, } \\
\text { GalNac-GD1a }\end{array}$ & $\begin{array}{l}\text { Discovered in China, less common } \\
\text { than AIDP in the West (Shoenfeld and } \\
\text { Meroni, 2012; Dimachkie and Barohn, } \\
\text { 2013) }\end{array}$ \\
\hline MFS & Ophthalmoplegia, ataxia, areflexia & $\begin{array}{l}\text { Auto antibodies against } \\
\text { nerve gangliosides }\end{array}$ & GQ1b & $\begin{array}{l}\text { 5-10\% cases in West but up to } 25 \% \\
\text { in Japan (Shoenfeld and Meroni, } \\
\text { 2012; Dimachkie and Barohn, 2013) }\end{array}$ \\
\hline
\end{tabular}

However, $\mathrm{T}_{\mathrm{H}} 2$ type cytokines IL-10 and TGF- $\beta$ are associated with receding EAN/GBS symptoms (Zhu et al., 1998). Both Tcell mediated and humoral immunity seems to be playing a role in GBS. In Acute Inflammatory Demyelinating Polyneuropathy (AIDP) variant, activated T-cells, upon antigen presentation by macrophages, cross the blood-nerve barrier (BNB) and release cytokines that activate endoneural macrophages, damaging the compact myelin. Alternatively either by directly recognizing a pathogenic epitope or elicited by $\mathrm{T}$-cell, B-cells produce antibodies to the cross-reactive axolemmal autoantigens and by fixing a complement leads to the damage of Schwann cells and/or axons, leading to Acute Motor Axonal Neuropathy (AMAN), the more severe Acute Motor and Sensory Axonal Neuropathy (AMSAN), or Miller Fisher Syndrome (MFS) (Hughes and Cornblath, 2005). The most common autoantigens are GM1, GM1a, and GD1a (Dimachkie and Barohn, 2013). Due to these variants and their diverse pathology and pathogenesis, GBS is now considered a group of heterogeneous conditions with similar clinical phenotypes (Kieseier et al., 2012). GBS has been considered a unique autoimmune disorder due to the fact that unlike most other neuronal autoimmune disorders, it is monophasic and that its occurrence has been found to correspond to immunosuppression in the patient (Steiner et al., 2010). The antecedent causative organisms mostly linked with GBS include C. jejuni ( $\approx 38 \%$ ) (Kaldor and Speed, 1984), $M$. pneumonia $(\approx 21 \%$ ) (Sharma et al., 2011). Infections by most or all of these agents are characterized by immunosuppression either as a primary result of the infection or as a secondary effect.

\section{EUBIOTIC GUT TO CURE GUILLAIN-BARRÉ SYNDROME}

Infection by C. jejuni, M. pneumonia, and viruses mentioned above also shows a differential effect on Treg and $\mathrm{T}_{\mathrm{H}} 1$ cell populations with infected individuals showing a reduced Treg cell presence (Steiner et al., 2010). Besides, there is evidence of $C$. jejuni colonization being exacerbated by a shift in the microbiota (characterized by increased Escherichia coli load in the gut) upon infection by Toxolasma gondii (Haag et al., 2012) and its alleviation by probiotic strain Lactobacillus helveticus strain
R0052 (Wine et al., 2009). With studies pointing toward probiotic assisted increase in the population of anti-inflammatory Treg cells (Smits et al., 2005; Kwon et al., 2010), and probiotics modulating $\mathrm{T}_{\mathrm{H}} 1$ (and $\mathrm{T}_{\mathrm{H}} 17$ )/ $\mathrm{T}_{\mathrm{H}} 2$ balance (Torii et al., 2007; Tanabe, 2013) it may be worth testing whether this increase in Treg cells reduces post infection autoimmunity in any way. It may not be wrong to expect a Treg cell mediated immune homeostasis of both the humoral (Wing and Sakaguchi, 2014) and cellular kind (Shevach, 2009), produced as a result of probiotic induced gut eubiosis.

\section{CONCLUSION}

GBS is a rare autoimmune disease effecting 2-4 people per 100,000 . Being a rare condition it is neglected by the big pharmaceutical companies, as well as academic researchers searching for better treatments. Although the treatments are available in the form of intravenous immunoglobulin (IVIg) administration and plasma exchange, they become quite expensive, especially in the developing countries. Added to it the poor prognosis of the disease, there is a need for cheaper alternatives to the currently available treatments. Probiotics have been shown to be effective in treatment of several intestinal and extra-intestinal autoimmunities, as they act by replenishing the Treg cells in the immune system that have been shown to promote the immune system homeostasis. There is ample reason to believe that GBS also is a result of altered immune homeostasis caused by infection due to an antecedent infection. Thus, promoting the production of Treg cells may help cure GBS by acting against both $\mathrm{T}$ - cell mediated and humoral autoimmunity of the PNS.

\section{AUTHOR CONTRIBUTIONS}

The author AS claims the sole responsibility of researching and writing this article.

\section{ACKNOWLEDGMENTS}

The article is dedicated to Ms. Priyanka Saxena, my cousin, diagnosed with GBS and went through a painful recovery 
using conventional methods. The idea to write this article was conceived while visiting her at the hospital and was developed further while attending a symposium on Probiotics - From Bench to Community, organised by Yakult India Microbiota and

\section{REFERENCES}

Alard, P., Parnell, S., Manirarora, J., Kosiewicz, M., and Atay, S. (2009). Probiotics control lupus progression via induction of regulatory cells and IL-10 production. J. Immunol. 182, 50.30 .

Allos, B. M. (1997). Association between Campylobacter infection and GuillainBarré syndrome. J. Infect. Dis. 176(Suppl. 2), S125-S128. doi: 10.1086/513783

Berger, A. (2000). Th1 and Th2 responses: what are they? Br. Med. J. 321:424. doi: 10.1136/bmj.321.7258.424

Bollrath, J., and Powrie, F. (2013). Feed your tregs more fiber. Science 341, 463-464. doi: $10.1126 /$ science. 1242674

Calcinaro, F., Dionisi, S., Marinaro, M., Candeloro, P., Bonato, V., Marzotti, S., et al. (2005). Oral probiotic administration induces interleukin-10 production and prevents spontaneous autoimmune diabetes in the non-obese diabetic mouse. Diabetologia 48, 1565-1575. doi: 10.1007/s00125-005-1831-2

Carabotti, M., Scirocco, A., Maselli, M. A., and Severi, C. (2015). The gut-brain axis: interactions between enteric microbiota, central and enteric nervous systems. Ann. Gastroenterol. 28, 203-209.

Damsker, J. M., Hansen, A. M., and Caspi, R. R. (2010). Th1 and Th17 cells: adversaries and collaborators. Ann. N.Y. Acad. Sci. 1183, 211-221. doi: 10.1111/j.1749-6632.2009.05133.x

Dimachkie, M. M., and Barohn, R. J. (2013). Guillain-Barré syndrome and variants. Neurol. Clin. 31, 491-510. doi: 10.1016/j.ncl.2013.01.005

Erickson, K. L., and Hubbard, N. E. (2000). Probiotic immunomodulation in health and disease. J. Nutr. 130, 403S-409S.

Gagliani, N., Vesely, M. C. A., Iseppon, A., Brockmann, L., Xu, H., Palm, N. W., et al. (2015). Th17 cells transdifferentiate into regulatory $\mathrm{T}$ cells during resolution of inflammation. Nature 523, 221-225. doi: 10.1038/nature 14452

Geier, M. R., Geier, D. A., and Zahalsky, A. C. (2003). Influenza vaccination and Guillain Barre syndrome? Clin. Immunol. 107, 116-121. doi: 10.1016/S15216616(03)00046-9

Gold, R., Hartung, H. P., and Toyka, K. V. (2000). Animal models for autoimmune demyelinating disorders of the nervous system. Mol. Med. Today 6, 88-91. doi: 10.1016/S1357-4310(99)01639-1

Goldschmidt, B., Menonna, J., Fortunato, J., Dowling, P., and Cook, S. (1980). Mycoplasma antibody in guillain-barre syndrome and other neurological disorders. Ann. Neurol. 7, 108-112. doi: 10.1002/ana.410070203

Grogan, D. (2015). The microbes within. Nature 518, S2-S2. doi: 10.1038/518S2a

Haag, L.-M., Fischer, A., Otto, B., Plickert, R., Kühl, A. A., Göbel, U. B., et al. (2012). Intestinal microbiota shifts towards elevated commensal Escherichia coli loads abrogate colonization resistance against Campylobacter jejuni in mice. PLoS ONE 7:e35988. doi: 10.1371/journal.pone.0035988

Hemarajata, P., and Versalovic, J. (2013). Effects of probiotics on gut microbiota: mechanisms of intestinal immunomodulation and neuromodulation. Ther. Adv. Gastroenterol. 6, 39-51. doi: 10.1177/1756283X12459294

Hughes, R. A., and Cornblath, D. R. (2005). Guillain-Barré syndrome. Lancet 366, 1653-1666. doi: 10.1016/S0140-6736(05)67665-9

Jacobs, B. C., Rothbarth, P. H., van der Meché, F. G., Herbrink, P., Schmitz, P. I., de Klerk, M. A., et al. (1998). The spectrum of antecedent infections in Guillain-Barré syndrome: a case-control study. Neurology 51, 1110-1115. doi: 10.1212/WNL.51.4.1110

Kaldor, J., and Speed, B. R. (1984). Guillain-Barré syndrome and Campylobacter jejuni: a serological study. Br. Med. J. (Clin. Res. Ed.) 288, 1867-1870. doi: 10.1136/bmj.288.6434.1867

Kieseier, B. C., Lehmann, H. C., and Hörste, G. M. Z. (2012). Autoimmune diseases of the peripheral nervous system. Autoimmun. Rev. 11, 191-195. doi: 10.1016/j.autrev.2011.05.011

Kueffel, N., Ziolkowski, J., and Haslberger, A. (2013). Microbiota and diseases of the nervous system. J. Ernahrungsmedizin 15, 18-20.

Kwon, H.-K., Lee, C.-G., So, J.-S., Chae, C.-S., Hwang, J.-S., Sahoo, A., et al. (2010). Generation of regulatory dendritic cells and CD4+Foxp3 $+\mathrm{T}$ cells by probiotics
Probiotic Science Foundation. No funds were utilized for the research that went into writing this article. The publication of this article has been facilitated by the grant of a full waiver of publishing fees by Frontiers.

administration suppresses immune disorders. Proc. Natl. Acad. Sci. U.S.A. 107, 2159-2164. doi: 10.1073/pnas.0904055107

Lavasani, S., Dzhambazov, B., Nouri, M., Fåk, F., Buske, S., Molin, G., et al. (2010). A novel probiotic mixture exerts a therapeutic effect on experimental autoimmune encephalomyelitis mediated by IL-10 producing regulatory $\mathrm{T}$ cells. PLoS ONE 5:e9009. doi: 10.1371/journal.pone.0009009

Lee, Y. K., Menezes, J. S., Umesaki, Y., and Mazmanian, S. K. (2011). Proinflammatory T-cell responses to gut microbiota promote experimental autoimmune encephalomyelitis. Proc. Natl. Acad. Sci. U.S.A. 108(Suppl. 1), 4615-4622. doi: 10.1073/pnas.1000082107

Li, S., Jin, T., Zhang, H.-L., Yu, H., Meng, F., Concha Quezada, H., et al. (2014). Circulating Th17, Th22, and Th1 cells are elevated in the Guillain-Barré syndrome and downregulated by IVIg treatments. Mediators Inflamm. 2014, 1-10. doi: 10.1155/2014/740947

Li, S., Yu, M., Li, H., Zhang, H., and Jiang, Y. (2012). IL-17 and IL-22 in cerebrospinal fluid and plasma are elevated in Guillain-Barré Syndrome. Mediators Inflamm. 2012, 1-7. doi: 10.1155/2012/260473

Liang, S. L., Wang, W. Z., Huang, S., Wang, X. K., Zhang, S., and Wu, Y. (2012). Th17 helper cell and T-cell immunoglobulin and mucin domain 3 involvement in Guillain-Barré syndrome. Immunopharmacol. Immunotoxicol. 34, 1039-1046. doi: 10.3109/08923973.2012.697469

Louveau, A., Smirnov, I., Keyes, T. J., Eccles, J. D., Rouhani, S. J., Peske, J. D., et al. (2015). Structural and functional features of central nervous system lymphatic vessels. Nature 523, 337-341. doi: 10.1038/nature14432

Mack, D. R. (2005). Probiotics-mixed messages. Can. Fam. Physician 51, 1455-1457, 1462-1464.

Manirarora, J. N., Parnell, S. A., Atay, S., Kosiewicz, M. M., and Alard, P. (2008). Probiotics protect (NZBxNZW)F1 mice against lupus by a mechanism involving IL-10 production by dendritic cells and regulatory cells. FASEB J. 22.

Matsuzaki, T., Takagi, A., Ikemura, H., Matsuguchi, T., and Yokokura, T. (2007). Intestinal microflora: probiotics and autoimmunity. J. Nutr. 137, 798S-802S.

Maynard, C. L., Elson, C. O., Hatton, R. D., and Weaver, C. T. (2012). Reciprocal interactions of the intestinal microbiota and immune system. Nature 489, 231-241. doi: 10.1038/nature11551

Pontali, E., Feasi, M., Crisalli, M. P., and Cassola, G. (2011). Guillain-Barré Syndrome with fatal outcome during HIV-1-Seroconversion: a case report. Case Rep. Infect. Dis. 2011, 1-4. doi: 10.1155/2011/972096

Sakaguchi, S., Wing, K., Onishi, Y., Prieto-Martin, P., and Yamaguchi, T. (2009). Regulatory T cells: how do they suppress immune responses? Int. Immunol. 21, 1105-1111. doi: 10.1093/intimm/dxp095

Schmidt, C. (2015). Mental health: thinking from the gut. Nature 518, S12-S15. doi: $10.1038 / 518$ S13a

Sharma, M. B., Chaudhry, R., Tabassum, I., Ahmed, N. H., Sahu, J. K., Dhawan, B., et al. (2011). The presence of Mycoplasma pneumoniae infection and GM1 ganglioside antibodies in Guillain-Barré syndrome. J. Infect. Dev. Ctries. 5, 459-464. doi: 10.3855/jidc. 1847

Sheil, B., Shanahan, F., and O'Mahony, L. (2007). Probiotic effects on inflammatory bowel disease. J. Nutr. 137, 819S-824S.

Shevach, E. M. (2009). Mechanisms of foxp3+ T regulatory cell-mediated suppression. Immunity 30, 636-645. doi: 10.1016/j.immuni.2009.04.010

Shoenfeld, Y., and Meroni, P.-L. (2012). The General Practice Guide to Autoimmune Diseases. Lengerich: Pabst Science Publishers.

Sivadon-Tardy, V., Orlikowski, D., Porcher, R., Sharshar, T., Durand, M. C., Enouf, V., et al. (2009). Guillain-Barré syndrome and influenza virus infection. Clin. Infect. Dis. 48, 48-56. doi: 10.1086/594124

Smits, H. H., Engering, A., van der Kleij, D., de Jong, E. C., Schipper, K., van Capel, T. M. M., et al. (2005). Selective probiotic bacteria induce IL-10producing regulatory $\mathrm{T}$ cells in vitro by modulating dendritic cell function through dendritic cell-specific intercellular adhesion molecule 3-grabbing nonintegrin. J. Allergy Clin. Immunol. 115, 1260-1267. doi: 10.1016/j.jaci.2005. 03.036 
Steiner, I., Rosenberg, G., and Wirguin, I. (2010). Transient immunosuppression: a bridge between infection and the atypical autoimmunity of GuillainBarré syndrome? Clin. Exp. Immunol. 162, 32-40. doi: 10.1111/j.13652249.2010.04223. $\mathrm{x}$

Tanabe, S. (2013). The effect of probiotics and gut microbiota on Th17 Cells. Int. Rev. Immunol. 32, 511-525. doi: 10.3109/08830185.2013.839665

Torii, A., Torii, S., Fujiwara, S., Tanaka, H., Inagaki, N., and Nagai, H. (2007). Lactobacillus Acidophilus strain L-92 regulates the production of Th1 cytokine as well as Th2 cytokines. Allergol. Int. 56, 293-301. doi: 10.2332/allergolint.O06-459

Wagner, R. D., Johnson, S. J., and Kurniasih Rubin, D. (2009). Probiotic bacteria are antagonistic to Salmonella enterica and Campylobacter jejuni and influence host lymphocyte responses in human microbiota-associated immunodeficient and immunocompetent mice. Mol. Nutr. Food Res. 53, 377-388. doi: 10.1002/mnfr.200800101

Walker, W. A. (2008). Mechanisms of action of probiotics. Clin. Infect. Dis. 46, S87-S91. doi: 10.1086/523335

Wang, X., Ma, C., Wu, J., and Zhu, J. (2013). Roles of T helper 17 cells and interleukin-17 in neuroautoimmune diseases with emphasis on multiple sclerosis and Guillain-Barré syndrome as well as their animal models. J. Neurosci. Res. 91, 871-881. doi: 10.1002/jnr.23233

Wine, E., Gareau, M. G., Johnson-Henry, K., and Sherman, P. M. (2009). Strain-specific probiotic (Lactobacillus helveticus) inhibition of Campylobacter jejuni invasion of human intestinal epithelial cells. FEMS Microbiol. Lett. 300, 146-152. doi: 10.1111/j.1574-6968.2009.01781.x
Wing, J. B., and Sakaguchi, S. (2014). Foxp3+ Treg cells in humoral immunity. Int Immunol. 26, 61-69. doi: 10.1093/intimm/dxt060

Wu, X., Wang, J., Liu, K., Zhu, J., and Zhang, H.-L. (2015). Are Th17 cells and their cytokines a therapeutic target in Guillain-Barré syndrome? Expert Opin. Ther. Targets. doi: 10.1517/13543776.2016.1111337. [Epub ahead of print].

Xu, L., Kitani, A., Fuss, I., and Strober, W. (2007). Cutting edge: regulatory t cells induce CD4+CD25-Foxp3- T Cells or are self-induced to become Th17 Cells in the absence of exogenous TGF-beta. J. Immunol. 178, 6725-6729. doi: 10.4049/jimmunol.178.11.6725

Zhu, J., Mix, E., and Link, H. (1998). Cytokine production and the pathogenesis of experimental autoimmune neuritis and Guillain-Barré syndrome. J. Neuroimmunol. 84, 40-52. doi: 10.1016/S0165-5728(97) 00238-5

Conflict of Interest Statement: The author declares that the research was conducted in the absence of any commercial or financial relationships that could be construed as a potential conflict of interest.

Copyright (C) 2016 Saxena. This is an open-access article distributed under the terms of the Creative Commons Attribution License (CC BY). The use, distribution or reproduction in other forums is permitted, provided the original author(s) or licensor are credited and that the original publication in this journal is cited, in accordance with accepted academic practice. No use, distribution or reproduction is permitted which does not comply with these terms. 